\title{
Using accreditation standards as a framework to evaluate and improve a community-based diabetes self-management education program.
}

\author{
Neva White \\ Center for Urban Health, United States; School of Nursing, Thomas Jefferson University Hospital, \\ Neva.White@jefferson.edu \\ Mary Lou Manning \\ School of Nursing, Thomas Jefferson University Hospital, MaryLou.Manning@jefferson.edu \\ Rickie Brawer \\ Center for Urban Health, United States \\ dambersthisumbl additional works at: https://jdc.jefferson.edu/dnpp \\ Center for Urban Health, United States \\ Part of the Other Medical Specialties Commons

\section{Let us know how access to this document benefits you}

\section{Recommended Citation}

White, Neva; Manning, Mary Lou; Brawer, Rickie; and Plumb, James, "Using accreditation standards as a framework to evaluate and improve a community-based diabetes selfmanagement education program." (2014). Department of Nursing papers and presentations.

Paper 15.

https://jdc.jefferson.edu/dnpp/15

This Article is brought to you for free and open access by the Jefferson Digital Commons. The Jefferson Digital Commons is a service of Thomas Jefferson University's Center for Teaching and Learning (CTL). The Commons is a showcase for Jefferson books and journals, peer-reviewed scholarly publications, unique historical collections from the University archives, and teaching tools. The Jefferson Digital Commons allows researchers and interested readers anywhere in the world to learn about and keep up to date with Jefferson scholarship. This article has been accepted for inclusion in Department of Nursing papers and presentations by an authorized administrator of the Jefferson Digital Commons. For more information, please contact: JeffersonDigitalCommons@jefferson.edu. 


\title{
Using Accreditation Standards as a Framework to Evaluate and Improve a Community-Based Diabetes Self-Management Education Program
}

\author{
Neva White, DNP, CRNP, CDE, Mary Lou Manning, RN, PhD, CPNP, ${ }^{2}$ Rickie Brawer, PhD, MPH, \\ and James Plumb, MD, MPH'
}

\begin{abstract}
Diabetes self-management education is an essential component of diabetes clinical management, and community-based programs are an effective intervention for improving glycemic control among adults living with diabetes. The National Standards for Diabetes Self-Management Education and Support are designed to define quality diabetes self-management education and support, and to assist diabetes educators to provide evidence-based education and self-management support. These standards are used in the field for recognition and accreditation. This article presents the results of a program evaluation conducted by the Center for Urban Health at the Thomas Jefferson University and Hospital, examines the outcomes of the community-based diabetes self-management program, and uses the standards as the evaluation framework. (Population Health Management 2014;17:8-12)
\end{abstract}

\section{Introduction}

D IABETES AFFECTS MORE THAN $8.3 \%$ of adults in the United States, and diabetes-related care accounts for $11 \%$ of all US health care expenditures. ${ }^{1,2}$ Complications of diabetes include cardiovascular disease, retinopathy, neuropathy, nephropathy, and cerebrovascular disease, as well as depression and other mental health conditions. ${ }^{3}$ To prevent complications and achieve optimal health, the person living with diabetes must understand and engage in behaviors that promote disease management. ${ }^{4,5}$ Structured diabetes education has been shown to improve long-term complications associated with disease morbidity and mortality, and diabetes self-management education (DSME) has emerged as a significant intervention to promote disease management, especially in high-risk populations. ${ }^{6-8}$ Healthy People serves as the foundation for prevention efforts across the US Department of Health and Human Services. Reducing the disease and economic burden of diabetes and improving the quality of life for all persons who have or are at risk for diabetes is one of its 2020 goals. ${ }^{9}$ One way to advance this goal is to increase the proportion of individuals diagnosed with diabetes who receive formal diabetes education.

DSME is the ongoing process of facilitating the knowledge, skill, and ability necessary for prediabetes and diabetes self-care, with the ultimate goal of sustained behavior change that supports improved health and decreased complications while reducing medical expenditures and lost productivity associated with diabetes complications. ${ }^{6,10}$ The process incorporates the needs, goals, and life experiences of the individual and is guided by evidence-based standards. The overall DSME objectives are to support informed decision making, self-care behaviors, problem solving, and active collaboration with the health care team and to improve clinical outcomes, health status, and quality of life. ${ }^{6} \mathrm{Al}-$ though it is well documented that diabetes education contributes to improved health outcomes, only one third to one half of individuals with diabetes in the United States receive diabetes self-management education. ${ }^{9}$

The DSME standards consist of 10 areas focused on DSME program structure, process, and outcomes. Led by the American Association of Diabetes Educators (AADE) and the American Diabetes Association, the standards are reviewed every 5 years for appropriateness, relevance, and scientific evidence by a Task Force comprised of key stakeholders and experts within the diabetes education community. In 2012, each standard was revised to include elements of behavioral, educational, psychosocial, or clinical support. Table 1 compares the 2007 and 2012 Standards. The 2012 Standards also emphasize the importance of education and support of people with prediabetes.

Providing DSME in community settings, such as community centers, faith institutions, recreation centers, schools,

${ }^{1}$ Center for Urban Health, and ${ }^{2}$ School of Nursing, Thomas Jefferson University Hospital, Philadelphia, Pennsylvania. 
Table 1. Comparison of 2007 and 2012 National Standards for Diabetes Self Management EDUCATION (AND SUPPORT) $)^{6,11}$

$\begin{array}{cc}2007 \text { National Standards for Diabetes } & \text { Self-Management Education } \\ \text { Standard } & \text { Self-Management Education and Support }\end{array}$

Standard 1 Structure

The DSME entity will have documentation of its organizational structure, mission statement, and goals and will recognize and support quality DSME as an integral component of diabetes care.

\section{Standard 2 Structure}

The DSME entity shall appoint an advisory group to promote program quality. This group shall include representatives from the health professions, people with diabetes, the community, and other stakeholders.

Standard 3 Structure

The DSME entity will determine the diabetes educational needs of the target population(s) and identify resources necessary to meet these needs.

\section{Standard 4 Structure}

A coordinator will be designated to oversee the planning, implementation, and evaluation of diabetes self-management education. The coordinator will have academic or experiential preparation in chronic disease care and education and in program management.

Standard 5 Process

Diabetes self-management education will be provided by 1 or more instructors. The instructors will have recent educational and experiential preparation in education and diabetes management or will be a certified diabetes educator. The instructor(s) will obtain regular continuing education in the field of diabetes management and education. At least 1 of the instructors will be a registered nurse, dietitian, or pharmacist. A mechanism must be in place to ensure that the participants' needs are met if those needs are outside the instructors' scope of practice and expertise.

Standard 6 Process

A written curriculum reflecting current evidence and practice guidelines, with criteria for evaluating outcomes, will serve as the framework for the DSME entity. The assessed needs of the individual with prediabetes and diabetes will determine which of the content areas are to be provided.

Standard 7 Process

An individual assessment and education plan will be developed collaboratively by the participant and instructor(s) to direct the selection of appropriate educational interventions and self-management support strategies. The assessment and education plan and the intervention and outcomes will be documented in the education record.

Standard 8 Process

A personalized follow-up plan for ongoing selfmanagement support will be developed collaboratively by the participant and instructor(s) The patient's outcomes and goals and the plan for ongoing self-management support will be communicated to the referring provider.
Internal structure

The providers of DSME will document an organizational structure, mission statement, and goal. For those providers working within larger organizations, that organization will recognize and support quality DSME as an integral component of diabetes care.

External input

The provider(s) of DSME will seek ongoing input from external stakeholders and experts in order to provide program quality.

Access

The provider(s) of DSME will determine who to serve, how best to deliver diabetes education to that population, and what resources can provide ongoing support for that population.

Program coordinator

A coordinator will be designated to oversee the DSME program. The coordinator will have oversight responsibility for the planning, implementation, and evaluation of education services.

\section{Instructional staff}

One or more instructors will provide DSME and when applicable, DSMS. At least 1 of the instructors responsible for designing and planning DSME and DSMS will be an RN, RD, or pharmacist with training and experience pertinent to DSME, or another professional with certification in diabetes care and education, such as a CDE, or BC-ADM. Other health workers can contribute to DSME and provide DSMS with appropriate training in diabetes and with supervision and support.

\section{Curriculum}

A written curriculum reflecting current evidence and practice guidelines, with criteria for evaluating outcomes, will serve as the framework for the DSME program. The needs of the individual participant will determine which parts of the curriculum will be provided to the individual.

\section{Individualization}

The diabetes self-management, education, and support needs of each participant will be assessed by 1 or more instructors. The participant and instructor(s) together will then develop an individualized education and support plan focused on behavior change.

Ongoing support

The participant and instructor(s) will together develop a personalized follow-up plan for ongoing selfmanagement support. The participant's outcomes and goals and the plan for ongoing self-management support will be communicated to other members of the health care team. 
TABle 1. (CONTINUEd)

\begin{tabular}{|c|c|c|}
\hline Standard & $\begin{array}{l}2007 \text { National Standards for Diabetes } \\
\text { Self-Management Education }\end{array}$ & $\begin{array}{l}2012 \text { National Standards for Diabetes } \\
\text { Self-Management Education and Support }\end{array}$ \\
\hline Standard 9 & $\begin{array}{l}\text { Outcome } \\
\text { The DSME entity will measure attainment of patient- } \\
\text { defined goals and patient outcomes at regular } \\
\text { intervals using appropriate measurement techniques } \\
\text { to evaluate the effectiveness of the educational } \\
\text { intervention. }\end{array}$ & $\begin{array}{l}\text { Patient progress } \\
\text { The provider(s) of DSME and DSMS will monitor } \\
\text { whether participants are achieving their personal } \\
\text { diabetes self-management goals and other } \\
\text { outcomes(s) as a way to evaluate the effectiveness of } \\
\text { the educational intervention(s), using appropriate } \\
\text { measurement techniques. }\end{array}$ \\
\hline Standard 10 & $\begin{array}{l}\text { Outcome } \\
\text { The DSME entity will measure the effectiveness of the } \\
\text { education process and determine opportunities for } \\
\text { improvement using a written continuous quality } \\
\text { improvement plan that describes and documents a } \\
\text { systematic review of the entities' process and } \\
\text { outcome data. }\end{array}$ & $\begin{array}{l}\text { Quality improvement } \\
\text { The provider(s) of DSME will measure the } \\
\text { effectiveness of the education and support and look } \\
\text { for ways to improve any identified gaps in services } \\
\text { and quality using a systemic review of process and } \\
\text { outcome data. }\end{array}$ \\
\hline
\end{tabular}

BC-ADM, board certified-advanced diabetes management; CDE, certified diabetes educator; DSME, diabetes self-management education; DSMS, diabetes self-management support; RD, registered dietitian; $\mathrm{RN}$, registered nurse.

libraries, and senior centers, allows participants to share learning experiences with family and friends in familiar settings while providing opportunities to positively address issues of cultural competence and relevancy. ${ }^{12-15}$ Ideally, community partners take ownership of health promotion activities and participate in recruitment. There are opportunities for system change and health care improvement at the population level when community stakeholders are engaged in the DSME process. ${ }^{13,16}$

\section{Program description}

The Jefferson Center for Urban Health (CUH), launched in 1998, aims to improve the health and well-being of Philadelphia citizens by marshaling the resources of Thomas Jefferson University Hospitals, Thomas Jefferson University, and its Department of Family and Community Medicine. The Center actively partners with community organizations and neighborhoods and uses existing data sources, such as the Public Health Management Corporation's Household Health Survey, and input from community organizations and residents to determine and prioritize program offerings. Grants from local, state, national, government, and private organizations provide primary program funding sources. DSME, offered since 2000, is an established CUH program, aimed at reaching ethnically diverse adults in low-income environments. Over the years the program has evolved and grown from a free-ofcharge, open-to-the-public offering to a more planned, interactive, collaborative, and outcomes-based program. To identify program gaps and areas for improvement, the Center conducted a systematic DSME program assessment in 2011, using the 2007 Standards as the evaluation framework.

\section{Methods}

\section{Evaluation design and assessment tool}

The evaluation design for the DSME program included a structure evaluation (How is the DSME program organized?), a process evaluation (How are the components of the DSME program implemented?), and an outcome evaluation (What are the effects of the DSME program?). The design framework mirrored the 2007 Standards, which are divided into structure (Standards 1 through 4), process (Standards 5 through 8), and outcome (Standards 9 and 10). An assessment tool developed by the Diabetes Education Accreditation Program of the AADE, titled "Crosswalk NSDSME/DEAP," was used to assess each program area. The tool identifies the essential elements of each standard, and provides an essential elements checklist and comprehensive interpretive guidance. ${ }^{6}$ The tool can be found on the AADE Web site (www.diabeteseducator.org).

\section{Data source}

Data were extracted from a CUH computerized database, de-identified DSME participant class forms (pre and post class assessments of self-reported diabetes management knowledge, self-efficacy, and quality of life issues), $\mathrm{CUH}$ policy and procedure manuals, annual grant reports, and DSME curriculum and course attendance records for calendar years 2008-2010.

\section{Results \\ Program structure}

Standards 1 through 4 focus on program structure and required documentation that described diabetes education as a distinct component within the organization's structure, identified the program's mission and goals, indicated an engaged advisory board, identified the process to assess the unique needs of the target population and allocation of resources, and detailed the academic and experiential preparation of the program coordinator.

The CUH policy and procedure manual, last updated in 2008, was readily accessible and contained the CUH organizational structure, mission statement, and goals. However, goals and objectives for specific CUH programs, including the DSME program, were not written. Although the CUH had a strong history of partnering with community stakeholders, a formal advisory group was not in place. The well-qualified program coordinator was an adult nurse practitioner who had over 25 years of experience in chronic 
disease management, held a doctorate in nursing practice, and was certified by the National Certification Board for Diabetes Educators. Interestingly, the coordinator job description did not define specific DSME responsibilities.

The target population was clearly identified. A review of annual grant reports found that in 2008 the Thomas Jefferson University Hospital organized a Community Benefit Task Force and conducted an extensive community health programs needs assessment that included local data analysis, employee focus groups, partner input, and a literature review. The Task Force recommended focusing programs and resources on neighborhoods near the Jefferson campus where $20 \%$ or more of families were below the poverty level. Key findings suggested that individuals living with diabetes in the Jefferson Hospital service area were: (1) less likely to have access to healthy foods; (2) more likely to skip medication doses because of financial reasons; (3) more likely to experience issues with literacy and numeracy; (4) more likely to cancel a health care appointment because of lack of transportation; (5) more likely to have hypertension, high cholesterol, and be obese; (6) less likely to report safe places in the neighborhood to walk and engage in physical activity; and (7) more likely to report issues with healthy coping. In addition, a review of data from 285 de-identified pre-DSME class assessment records indicated that most DSME class participants were female $(78 \%)$, African American $(76 \%)$, older than 60 years of age (51\%), and had a diagnosis of type 2 diabetes (51\%). Since 2009, these data were used to determine the Center's DSME program target population.

\section{Program process}

Standards 5 through 8 focus on program process and required documentation related to instructional staff qualifications and the mechanisms for meeting participant needs outside the instructor's scope of practice; evidence of a curriculum tailored to meet the needs of the target population, including criteria for evaluating outcomes; and evidence of a collaborative educational approach comprised of participant assessment, goal setting, and education plan implementation and follow-up.

Instructional staff job descriptions were reviewed for qualifications and responsibilities. All instructors had a minimum of a master's degree in the health sciences (eg, nursing, health education) but, similar to the coordinator, the job descriptions did not define specific DSME responsibilities. The detailed DSME program's written curriculum, instructional methods, and materials were readily available and focused specifically on meeting the needs of the target population with consideration given to type and duration of diabetes, age, and group learning abilities. There was clear evidence that the curriculum was updated annually (and more often as needed) to reflect current evidence and practice guidelines. As required by the standards, the curriculum included the AADE's 7 (AADE7) self-management behaviors including: (1) healthy eating, (2) being active, (3) monitoring, (4) taking medication, (5) problem solving, (6) reducing risk, and (7) healthy coping. ${ }^{8}$

A review of the course and attendance records indicated that, during the 3-year period, 5-7 group-based sessions were held annually, most participants being self-referred. Program sessions consisted of three 60-90 min classes, conducted over
3-4 weeks, each covering a distinct topic or task, with a logical progression to the next class. Class size ranged from 10-15 participants. Approximately $75 \%$ of participants attended all 3 classes. Class 1 included an overview of diabetes disease, pathophysiology, and glucose monitoring principles. In this class, participants completed a self-monitoring glucose test and were given feedback and assistance as needed. Class 2 focused on nutrition and healthy eating. Class 3 focused on taking medications, reducing risks, and preventing, detecting, and treating acute complications. A review of class evaluations found few opportunities for collaborative, skill-based training that used consistent interactive methods. Criteria for evaluating immediate outcomes (eg, barriers to learning) and intermediate outcomes (eg, behavior change) were not included as part of the curriculum.

Participants were asked to complete a pre-assessment questionnaire prior to class 1 and a post assessment after class 3 . The assessment included relevant medical history, present health status, risk factors, diabetes knowledge and skill (pre and post), health beliefs and attitudes, and current health behaviors. There was no evidence that individual assessment and education plans were developed collaboratively by participants and instructor(s). Elements of the AADE7 self-care behaviors were found in the assessment; however, specific questions to address cultural influences, barriers to learning, socioeconomic factors, and health goals were limited. The post-assessment form documented some educational interventions and achievement of some learning goals. A major program gap was the absence of participant involvement in developing educational goals and learning objectives with the instructor(s).

\section{Program outcomes}

Standards 9 and 10 focus on program outcomes and required documentation of a system to collect individual and aggregate outcome measures, documentation that the data were used for individual-level educational interventions and program-level evaluation, and that program effectiveness was measured using a written continuous quality improvement (CQI) plan.

Although there were opportunities for participant followup through various CUH-sponsored diabetes initiatives, no evidence was found to suggest a consistent process to measure participant goal achievement or success in following selfcare recommendations beyond the final class of the DSME program session. Aggregate population outcome measures to guide programmatic services and CQI activities were not specific. Evaluation methods including data sources, data collection tools, and procedures were not utilized consistently. Data analysis, synthesis, and dissemination were limited. Data collection tools and processes were not explicitly defined. There was no written CQI plan. A major program gap was the absence of long-term participant outcome measures.

\section{Discussion}

Diabetes management is complex and challenging for both patients and health care professionals. However, the day-today management of diabetes is primarily in the hands of patients; therefore, they need education and skill building to perform successful self-management. Community-based DSME programs are complex interventions shown to be 
effective at enhancing self-care behaviors. Programs often are composed of various content and delivery components tailored to meet the needs of specific target populations and, as such, require ongoing evaluation to determine resource utilization and participant behavioral outcomes. Over the past 10 years, the CUH assessed program outcomes, reported data consistent with funding goals and objectives, and used findings to guide program implementation; however, in order to sustain the program and seek insurance reimbursement, accreditation is a requirement. Standards for DSME are used by the Diabetes Education Accreditation Program of the AADE and the American Diabetes Association's Education Recognition Program to accredit DSME programs and provide a practical framework for a community-based program evaluation. The framework is especially useful for those with minimal training in research methods or evaluation to transfer understanding of accreditation processes to conduct evaluation. ${ }^{17}$

Findings from this community-based DSME program evaluation found substantial compliance with standards related to program structure, moderate compliance with standards related to program process, and significant opportunities for improvement with standards related to program outcomes. The dynamic nature of community-based diabetes education presents significant barriers to collecting outcomes assessment (eg, time and resource utilization, access to medical records, participant literacy issues). Community-based programs open to the general public often enroll a very mobile population that presents challenges to follow-up and ongoing support. Based on the findings the CUH launched a quality improvement team, established an active community-based advisory committee including key stakeholders, reviewed and revised all job descriptions to include specific qualifications and responsibilities, revised the curriculum to include an assessment of learner needs and more interactive classroom strategies, and developed a formal mechanism to measure attainment of participant-defined goals and outcomes ( 1 month, 3 months, 6 months, and 1 year). To ensure collection of participant baseline health information (eg, A1c testing, body mass index, blood pressure), the program also added a pre-class health screening session including one-on-one counseling and assistance as needed. As a result of this evaluation, the CUH now has a comprehensive, continuous DSME program quality improvement plan helping the Center to understand the relationship between specific program elements and program outcomes.

\section{Author Disclosure Statement}

The authors declared no conflicts of interest with respect to the research, authorship, and/or publication of this article.

\section{References}

1. Centers for Disease Control and Prevention. National Diabetes Fact Sheet: National Estimates and General Information on Diabetes and Prediabetes in the United States, 2011. Atlanta, GA: US Department of Health and Human Services, Centers for Disease Control and Prevention; 2011.
2. Dall TM, Zhang Y, Chen YJ, Quick WW, Yang WG, Fogli J. The economic burden of diabetes. Health Aff (Millwood) 2011;29:297-303.

3. American Diabetes Association. Standards of medical care2013. Diabetes Care 2013;36:S11-S66.

4. Norris SL, Lau J, Smith SJ, Schmid CH, Engelgau MM. Selfmanagement education for adults with type 2 diabetes: A meta-analysis of effect on glycemic control. Diabetes Care 2002;25:1159-1171.

5. Lorig KR, Holman H. Self-management education: History, definition, outcomes, and mechanisms. Ann Behav Med 2003;26:1-7.

6. Haas L, Maryniuk, M, Beck J, et al. National standards for diabetes self-management education and support. Diabetes Educ 2012;38:619-629.

7. Fisher EB, Brownson CA, O'Toole ML, Anwuri VV, Shetty G. Perspectives on self-management from the diabetes initiative of the Robert Wood Johnson Foundation. Diabetes Educ 2007;33:216S-224S.

8. American Association of Diabetes Educators. AADE position statement. Individualization of diabetes self-management education: Diabetes Educ 2007;33:45-49.

9. US Department of Health and Human Services Office of Disease Prevention and Health Promotion. Healthy People 2020. Washington, DC: US Department of Health and Human Services; 2011.

10. Boren SA, Fitzner KA, Panhalkar PS, Specker JE. Costs and benefits associated with diabetes education: A review of the literature. Diabetes Educ 2009;35:72-96.

11. Funnell MM, Brown, TL, Childs BP, et al. National standards for diabetes self-management education. Diabetes Care 2012;35:S101-S108.

12. Norris SL, Nichols $P$, Caspersen CJ, et al. Increasing diabetes self-management education in community settings: A systematic review. Am J Prev Med 2002;22:39-66.

13. Task Force on Community Preventive Services. Recommendations for healthcare system and self-management education interventions to reduce morbidity and mortality from diabetes. Am J Prev Med 2002;22:10-14.

14. Samuel-Hodge CD, Keyserling TC, France R, et al. A churchbased diabetes self-management education program for African Americans with type 2 diabetes. Prev Chronic Dis 2006;3:A93.

15. Castro S, O’Toole M, Brownson C, Plessel K, Schauben L. A diabetes self-management program designed for urban American Indians. Prev Chronic Dis 2009;6:A131.

16. Gallivan J, Greenberg R, Brown C. The National Diabetes Education Program evaluation framework: How to design an evaluation of a multifaceted public health education program. Prev Chronic Dis 2008;5:A134.

17. Severance JH. Community health program evaluation using accreditation as a framework. Eval Health Prof 2009;32:59-68.

Address correspondence to: Neva White, DNP, CRNP, CDE Thomas Jefferson University Hospital 211 South $9^{\text {th }}$ Street, Suite 300-315 Philadelphia, Pa 19107

E-mail: Neva.White@jeffersonhospital.org 